\title{
Correction to: Unified compact numerical quadrature formulas for Hadamard finite parts of singular integrals of periodic functions
}

\section{Avram Sidi ${ }^{1}$}

Published online: 1 June 2021

(c) Istituto di Informatica e Telematica (IIT) 2021

\section{Correction to: Calcolo (2021) 58: 22 https://doi.org/10.1007/s10092-021-00407-8}

The original version of this article unfortunately contained mistakes. Due to typesetting errors factorial signs $\$ ! \$$ and semicolons in equations have been displayed incorrectly.

The original article has been corrected.

Publisher's Note Springer Nature remains neutral with regard to jurisdictional claims in published maps and institutional affiliations.

The original article can be found online at https://doi.org/10.1007/s10092-021-00407-8.

Avram Sidi

asidi@cs.technion.ac.il

http://www.cs.technion.ac.il/ asidi

1 Computer Science Department, Technion - Israel Institute of Technology, 32000 Haifa, Israel 